Nov 2017 a Abr $2018-v .8-n .1$

\title{
Extração e estudo da cinética de secagem da fécula de batata-doce
}

A realização desse trabalho objetivou a extração da fécula de batata doce e o estudo da cinética de secagem, avaliando também as suas características físicoquímicas. A secagem da batata-doce foi realizada em estufa de circulação forçada de ar a temperatura de 60,70 e $80^{\circ} \mathrm{C}$. Para representar as curvas de secagem utilizaram-se modelos matemáticos existentes na literatura, os modelos utilizados foram o de Henderson e Pabis, Midilli e Kucuk e Page. Os modelos em estudo ajustaram-se bem aos dados experimentais, sendo que os modelos de Midilli e Kucuk e Page apresentaram um coeficiente de determinação acima de 0,99. A batata-doce apresentou um valor médio de cinzas de $0,22 \%$, e um percentual de umidade de $4,44 \%$, atendendo as especificações do Instituto Internacional em Amidos, Resolução CNNPA no12 ANVISA/MS.

Palavras-chave: Amido; Análises físico-químicas; Modelagem matemática.

\section{Extraction and study of drying kinetics of sweet potato starch}

This work aimed at the extraction of sweet potato starch and the study of drying kinetics, also evaluating their physicochemical characteristics. Drying of the sweet potato was carried out in a forced circulation oven at a temperature of 60,70 and $80^{\circ} \mathrm{C}$. To represent the kinetics of drying, we used mathematical models in the literature, the models used were those of Henderson and Pabis, Midilli and Kucuk and Page. The three models under study fit well with the experimental data, so the models of Midilli and Kucuk and Page presenting a coefficient of determination above 0.99 . The sweet potato had an average ash value of $0.22 \%$, and a humidity percentage of $4.44 \%$, according to the International Institute of Starches specifications, CNNPA Resolution no 12 Anvisa / MS.

Keywords: Starch; Physicochemical analysis; Mathematical modeling.

Topic: Engenharia de Alimentos

Reviewed anonymously in the process of blind peer.
Received: $12 / 01 / 2018$

Approved: 24/04/2018
Karla Mamedes Viana

Universidade do Estado de Mato Grosso, Brasil

http://lattes.cnpq.br/3112720279667951

karla-mamedes@hotmail.com

Cesar Vinicius Toniciolli Rigueto (iD

Universidade do Estado de Mato Grosso, Brasil

http://lattes.cnpq.br/5053497434546209

http://orcid.org/0000-0003-2778-5170

cesartoniciolli@gmail.com

Rafael Tomiyama Borges

Universidade do Estado de Mato Grosso, Brasil

http://lattes.cnpq.br/7282595553723090

engrafaeltb@gmail.com
Chrystiellen Riama Martins Ribeiro

Universidade do Estado de Mato Grosso, Brasi

http://lattes.cnpq.br/1356348034090653

chrys ribeiro@hotmail.com

Claudinéia Aparecida Queli Gerald

Universidade do Estado de Mato Grosso, Brasil

http://lattes.cnpq.br/0165106391032005

claudigeraldi@onda.com.br
Referencing this:

VIANA, K. M.; RIGUETO, C. V. T.; BORGES, R. T.; RIBEIRO, C. R. M.; GERALDI, C. A. Q.. Extração e estudo da cinética de secagem da fécula de batata-doce. Natural Resources, v.8, n.1, p.1-8, 2019. DOI: http://doi.org/10.6008/CBPC2237-9290.2018.001.0001 


\section{INTRODUÇÃO}

Atualmente no Brasil, a maior parte da produção dos tubérculos é destinada ao consumo in natura, no entanto, a industrialização vem crescendo em todo o mundo, sendo uma alternativa prática e viável. Diante da importância da busca por novos amidos com características que atendam às exigências de um mercado em ascensão, a batata-doce e suas formas de processamento ainda são pouca explorada no Brasil (CARDOSO, 2005).

No ano de 2015, o Brasil produziu 595,9 toneladas em uma área de 44 hectares. A região Nordeste apresenta uma maior área plantada de cultivares de batata-doce, mas com um rendimento menor na produção em relação à região Sul. Isso se explica pelo fato de que grande parte do cultivo ainda é realizada de forma rudimentar, evidenciando a carência de orientação profissional do conhecimento técnico ao agricultor (SOUSA, 2012).

O Brasil, mesmo sendo um grande produtor de produtos hortícolas disponíveis a uma ampla parte da população, tem-se níveis admissíveis de perdas desses produtos devido a manejos inadequados desde a fase de colheita até o armazenamento, diante deste fato, observa-se uma necessidade de processos simples e baratos para oferecer meios para aumentar a conservação dos alimentos perecíveis (ALVES et al., 2010).

A secagem é uma das técnicas mais antigas usadas pelo homem para a preservação dos seus alimentos, reduzindo a atividade de água pelo processo de remoção da água presente em seu interior, comparando-a com outros métodos de conservação a desidratação fornece custos mais baixos e operações mais simples, a remoção da água diminui a atividade de água no produto inibindo o desenvolvimento de microrganismos e retardando deteriorações de origem físico-química e microbiológica (CANO-CHAUCA et al., 2004). Por esse motivo, esse trabalho objetivou a extração, secagem e caracterização físico-química da fécula de batata-doce, sendo que a importância de seu desenvolvimento além do interesse direto da indústria, foi a não existência na literatura de estudos específicos relacionados à secagem de fécula de batata-doce.

\section{METODOLOGIA}

\section{Obtenção da matéria prima}

As batatas foram adquiridas no comercio local de Barra do Bugres/MT, e lavadas em água corrente até eliminação total das impurezas, em seguida, foram higienizadas com água clorada. Após esta etapa, as mesmas foram raladas manualmente em ralador doméstico. A polpa foi lavada sucessivas vezes para a separação da fécula/bagaço, com o auxílio de peneiras. Após obter a fécula, esta foi lavada novamente para a retirada de possíveis impurezas (água vegetal e pequenas partículas de bagaço) que ainda ficaram das etapas anteriores.

Posterior ao processo de extração e purificação da fécula, esta foi desidratada a vácuo, com auxílio do funil e bomba de vácuo. A fécula desidratada foi peneirada para uniformidade dos grânulos, em seguida seca em estufa de convecção forçada (modelo CE-220/100, marca Cienlab), para a caracterização utilizou-se fécula de batata-doce seca nas temperaturas de 60,70 e 80 ㄷ․ 


\section{Análises físico-químicas}

As amostras foram distribuídas em placas de Petri com uma espessura de 2 a $4 \mathrm{~mm}$, e em seguida foram submetidas a secagem, em estufa de convecção forçada nas temperaturas de 60,70 e $80^{\circ} \mathrm{C}$. Decorrido o tempo necessário, as amostras foram retiradas das placas com o auxílio de uma espátula e acondicionadas em embalagem plástica, para uso posterior. As amostras de fécula de batata-doce foram submetidas às análises de umidade, $\mathrm{pH}$, cinzas, fator ácido e acidez, conforme a metodologia do Instituto Internacional em Amidos (INTERNATIONAL STARCH INSTITUTE, 1997). Todas as análises foram realizadas em triplicata.

\section{Cinética de secagem}

As curvas de secagem foram estabelecidas para as amostras submetidas às condições descritas, mediante acompanhamento da perda de umidade registrada através da variação da massa das amostras em intervalos de tempo de 15 em 15 minutos. As pesagens foram realizadas em balança semi-analítica com precisão de 0,0001g, marca Shimadzu, modelo ax200. Os ensaios foram prolongados até que atingissem as condições de equilíbrio (massa constante).

\section{Modelagem matemática}

Para analisar o comportamento da perda de umidade ao longo do tempo foram utilizados modelos semi-empíricos, considerando a umidade de equilíbrio como a umidade atingida quando a taxa de secagem se anula, foram calculadas as razões de umidade (RX). Logo, utilizou-se o programa Excel versão 2010 para ajustar os resultados aos modelos matemáticos de Henderson et al. (1961), Midilli et al. (2002) e Page (1949), conforme apresentados na Tabela 1.

Tabela 1: Modelos matemáticos empregados para descrever a cinética de secagem.

\begin{tabular}{|l|c|}
\hline Modelo & Equação \\
\hline Page & $R U=\exp \left(-k * t^{n}\right)$ \\
\hline Henderson e Pabis & $R U=\mathrm{a} \exp (-k * t)$ \\
\hline Midilli e Kucuk & $R U=\exp \left(-k * t^{n}\right) b * t$ \\
\hline
\end{tabular}

$\mathrm{RU}=$ razão do teor de água do produto, adimensional;

$\mathrm{t}=$ tempo de secagem, em $\mathrm{h} ; \mathrm{k}=$ coeficiente de secagem, em $\mathrm{s}^{1}$;

$\mathrm{a}, \mathrm{b}, \mathrm{n}$ e $\mathrm{k}=$ constantes do modelo, adimensional.

\section{RESULTADOS}

\section{Análises físico-químicas}

Os resultados das análises físico-químicas da fécula de batata-doce estão apresentados conforme a Tabela 2.

Tabela 2: Caracterização físico-química da fécula de batata-doce nas temperaturas de 60,70 e $80^{\circ} \mathrm{C}$.

\begin{tabular}{|c|c|c|c|}
\hline Análise & $\mathbf{6 0} \mathbf{C}$ & $\mathbf{7 0} \mathbf{C}$ & $\mathbf{8 0} \mathbf{C}$ \\
\hline Umidade (\%) & $4,44 \pm 0,06$ & $2,89 \pm 0,11$ & $1,60 \pm 0,01$ \\
\hline pH & $5,01 \pm 0,01$ & $5,20 \pm 0$ & $5,18 \pm 0,01$ \\
\hline Fator ácido & $0,5 \pm 0$ & $0,5 \pm 0$ & $0,5 \pm 0$ \\
\hline Acidez (\%) & $1,25 \pm 0$ & $1,25 \pm 0$ & $1,25 \pm 0$ \\
\hline Análise & $0,11 \pm 0,01$ & $0,06 \pm 0$ & $0,22 \pm 0,04$ \\
\hline
\end{tabular}




\section{Cinética de secagem}

A curva de secagem da amostra da fécula de batata-doce (Figura 1), está apresentada na forma adimensional do conteúdo de umidade (RX versus o tempo).

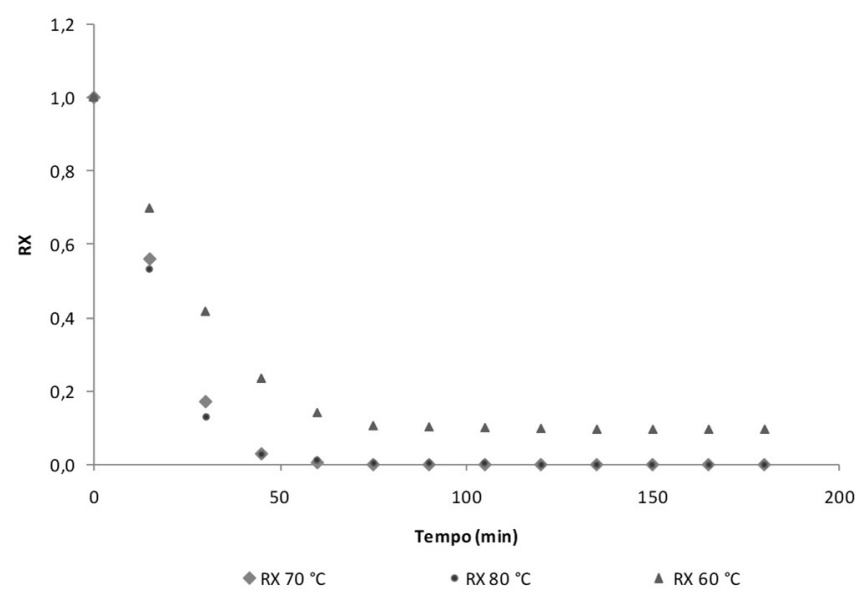

Figura 1: Curvas de secagem da fécula de batata-doce nas temperaturas de 60,70 e $80^{\circ} \mathrm{C}$.

\section{Modelagem matemática}

Os resultados dos ajustes dos parâmetros dos modelos matemáticos de Henderson e Pabis, Midilli e Kucuk, Page para as amostras da fécula de batata-doce secas a 60, 70380 으, estão apresentados nas Tabelas 3,4 e 5 , respectivamente.

Tabela 3: Parâmetros dos modelos matemáticos ajustados para a cinética de secagem da fécula de batata-doce a $60^{\circ} \mathrm{C}$.

\begin{tabular}{|c|c|c|}
\hline MODELO & PARÂMETROS & $\mathbf{6 0}{ }^{\circ} \mathbf{C}$ \\
\hline & $\mathrm{A}$ & 1,000032 \\
Henderson e Pabis & $\mathrm{k}\left(\mathrm{min}^{-1}\right)$ & 0,029178 \\
& Correlação & 0,988459 \\
& Erro & 0,883700 \\
\hline \multirow{3}{*}{ Midilli e Kucuk } & $\mathrm{A}$ & 1,000001 \\
& $\mathrm{~b}$ & 0,000576 \\
& $\mathrm{k}\left(\mathrm{min}^{-1}\right)$ & 0,011468 \\
& $\mathrm{n}$ & 1,288472 \\
& Correlação & 0,998832 \\
& Erro & 0,157752 \\
\hline & $\mathrm{k}\left(\mathrm{min}^{-1}\right)$ & 0,092539 \\
& $\mathrm{n}$ & 0,667848 \\
& Correlação & 0,974639 \\
\hline
\end{tabular}

Tabela 4: Parâmetros dos modelos matemáticos ajustados para a cinética de secagem da fécula de batata-doce a $70^{\circ} \mathrm{C}$.

\begin{tabular}{|c|c|c|}
\hline MODELO & PARÂMETROS & $\mathbf{7 0}^{\circ} \mathbf{C}$ \\
\hline & $\mathrm{A}$ & 1,000000 \\
Henderson e Pabis & $\mathrm{k}\left(\mathrm{min}^{-1}\right)$ & 0,058762 \\
& Correlação & 0,990416 \\
& Erro & 0,232192 \\
\hline \multirow{3}{*}{ Midilli e Kucuk } & $\mathrm{A}$ & 0,999999 \\
& $\mathrm{~b}$ & 0,000000 \\
& $\mathrm{k}\left(\mathrm{min}^{-1}\right)$ & 0,007515 \\
& $\mathrm{n}$ & 1,604745 \\
& Correlação & 0,999991 \\
& Erro & 0,005945 \\
\hline & $\mathrm{k}\left(\mathrm{min}^{-1}\right)$ & 0,007509 \\
& $\mathrm{n}$ & 1,604890 \\
& Correlação & 0,999991 \\
\end{tabular}


Tabela 5: Parâmetros dos modelos matemáticos ajustados para a cinética de secagem da fécula de batata-doce a $80^{\circ} \mathrm{C}$.

\begin{tabular}{|c|c|c|}
\hline MODELO & PARÂMETROS & $\mathbf{8 0}{ }^{\circ} \mathbf{C}$ \\
\hline & $\mathrm{A}$ & 1,000000 \\
Henderson e Pabis & $\mathrm{k}\left(\mathrm{min}^{-1}\right)$ & 0,067621 \\
& Correlação & 0,985857 \\
& Erro & 0,203591 \\
\hline \multirow{3}{*}{ Midilli e Kucuk } & $\mathrm{A}$ & 1,000001 \\
& $\mathrm{~b}$ & 0,000012 \\
& $\mathrm{k}\left(\mathrm{min}^{-1}\right)$ & 0,006419 \\
& $\mathrm{n}$ & 1,692667 \\
& $\mathrm{Correlação}$ & 0,999906 \\
& Erro & 0,032387 \\
\hline & $\mathrm{k}\left(\right.$ min $\left.^{-1}\right)$ & 0,008546 \\
& $\mathrm{n}$ & 1,586746 \\
& Correlação & 0,999760 \\
\hline
\end{tabular}

Nas Figuras 2, 3 e 4, estão apresentadas as curvas ajustadas segundo os modelos de Henderson e Pabis, Midilli e Kucuk, Page aos dados experimentais da cinética da fécula de batata-doce, nas condições de 60,70 e $80^{\circ} \mathrm{C}$, respectivamente.

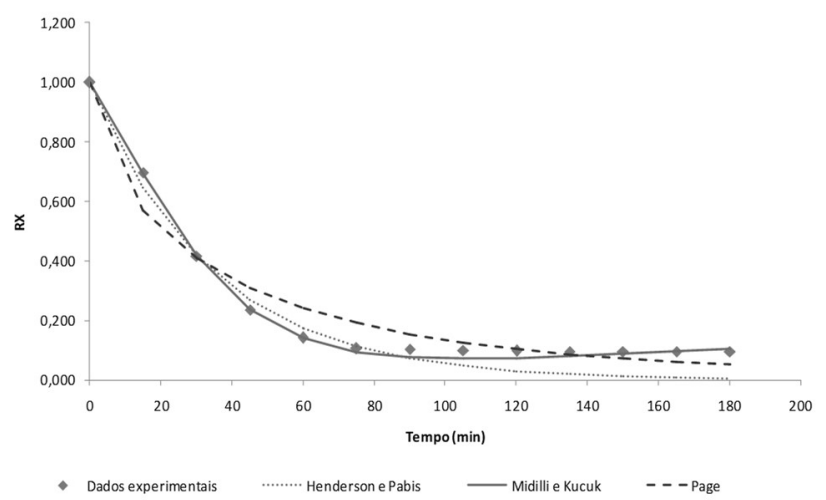

Figura 2: Ajuste do modelo de Handerson, Midilli e Page da fécula de batata-doce na temperatura de $60^{\circ} \mathrm{C}$.

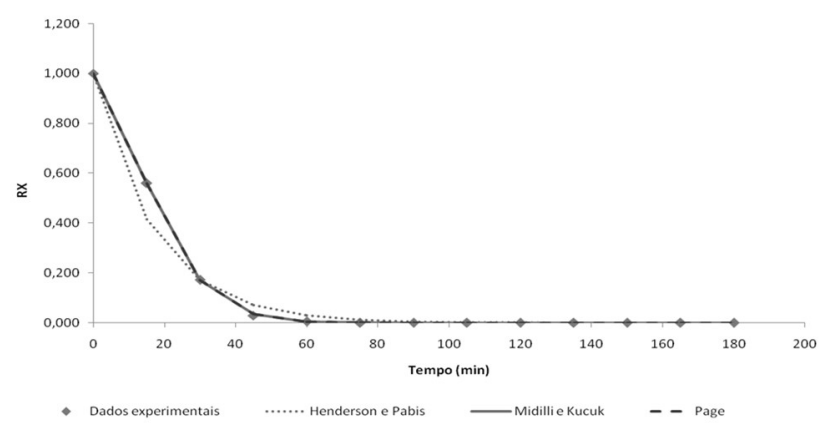

Figura 3: Ajuste do modelo de Handerson, Midilli e Page da fécula de batata-doce na temperatura de $70^{\circ} \mathrm{C}$

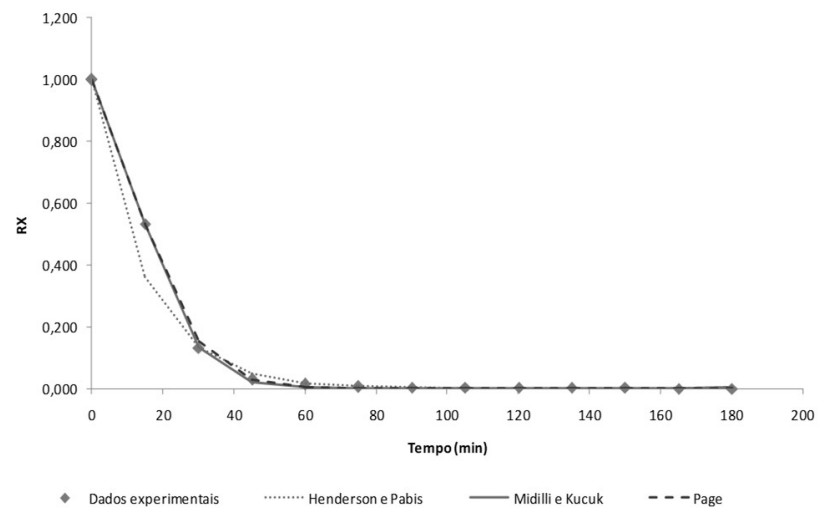

Figura 4: Ajuste do modelo de Handerson, Midilli e Page da fécula de batata-doce na temperatura de $80^{\circ} \mathrm{C}$. 


\section{DISCUSSÃO}

\section{Análises físico-químicas}

A fécula de batata-doce não possui uma legislação de regulamentação especifica. Portanto, obedece a Resolução CNNPA nำ12, de 1978 (ANVISA/MS), para produtos amiláceos, ingredientes para preparo de alimentos. Analisando a Tabela 2, nota-se que o teor de umidade da fécula de batata-doce encontra-se dentro do valor máximo estipulado pela Resolução CNNPA no12 (ANVISA, 1978), que é de 14\%. Portanto, féculas quando possuem umidade acima de $14 \%$ podem facilitar o desenvolvimento de microrganismos, como fungos e também não assegura a qualidade do produto, pois a água presente é o principal agente apara que ocorram reações enzimáticas e químicas, diminuindo a vida útil da fécula de batata-doce (SILVA, 2010).

Geraldi (2006), também encontrou uma umidade permitida pela ANVISA de 13\% para fécula de mandioca, essa variação de resultados pode ser explicada pela diferença de metodologia, pois a autora utilizou o aparelho de determinador de umidade por infravermelho. 0 teor de cinzas (Tabela 2), também se encontra dentro do valor máximo estipulado pela Resolução CNNPA no12 (ANVISA, 1978), que é de 0,50\%. 0 resultado obtido foi inferior ao encontrado por Borba (2005), que foi de 2,7\%, este autor realizou análises físico-químicas na farinha de batata-doce branca, e o presente estudo utilizou-se fécula de batata-doce roxa, esta diferença dos teores de cinzas podem ter ocorrido devido à variedade, tratos culturais, clima entre outros, podendo ter sido o fator resultante na diferença de resultados entre os trabalhos. Ainda, Souza (2016) encontrou um valor de 1,13\% de cinzas para purê desidratado de batata-doce.

Os valores de pH, fator ácido e acidez são comumente utilizados pelas indústrias de amidos e fécula, estas propriedades são de interesse, pois determinam à qualidade da fécula. Os valores obtidos estão de acordo com os dados publicados pela ABAM (Associação Brasileira dos Produtores de Mandioca). Para a análise de $\mathrm{pH}$, este deve ficar entre 5 e 6,5, abaixo de 5 significa que já ocorreu uma degradação microbiológica na raiz, antes da extração da fécula, e acima deste valor uma adulteração (com correção de produto químico), a acidez também está relacionada com a degradação da raiz, já o fator ácido deve ficar entre 2,5 e 3,5, e significa que a raiz foi devidamente processada não apresentando residual de água vegetal (água de constituição da raiz). Ressalta-se que, os resultados das análises físico-químicas encontradas neste estudo atendem aos padrões comerciais.

\section{Cinética de secagem}

Na Figura 1, pode-se observar que o período de secagem depende do tempo e da temperatura. Nas primeiras horas de secagem há uma queda significativa de umidade, pois parte dela está livre sobre a superfície da amostra, diante disto é facilmente removida. Para o restante do tempo, as diferenças diminuem em função da resistência interna ao transporte de umidade. Neste momento, a água presente na fécula de batata-doce se interage com os grupos polares das moléculas constituintes. Portanto, quanto maior for à temperatura de secagem mais facilmente a amostra entrará em equilíbrio, nas condições estudadas. 
Souza (2016) realizou o estudo da cinética de secagem de batata-doce em estufa de convecção forçada, onde obteve o equilíbrio da amostra em 8 horas. Santos et al. (2012), atingiu o equilíbrio da amostra em 10 horas, seu estudo da cinética de secagem de batata-doce foi realizado em um secador solar de bandeja. No presente estudo, nas condições de temperatura de 70 e $80^{\circ} \mathrm{C}$ a fécula de batata-doce atingiu o equilíbrio em 1 hora, e na temperatura de $60^{\circ} \mathrm{C}$ obteve o equilíbrio em $1 \mathrm{~h} 30 \mathrm{~min}$.

\section{Modelagem matemática}

Como podem ser observados nas Tabelas 3, 4, e 5 os três modelos apresentaram um baixo erro médio e uma alta correlação. Ainda, nas Figuras 2, 3 e 4, o perfil das curvas confirma que os três modelos em estudo se ajustaram aos dados experimentais, destacando-se os modelos de Page e de Midili e Kucuk que apresentaram correlações acima de 0,99 para as três condições em estudo.

Geraldi (2006) realizou o estudo da secagem da fécula de mandioca e confirmou que o modelo de Page foi o que apresentou melhor ajuste aos dados experimentais, para a secagem nas temperaturas de 80 , 90, 100, 110120 e 130 e $140{ }^{\circ} \mathrm{C}$, utilizando secagem por infravermelho. Santos et al (2012) também analisaram os três modelos para descrever a cinética de secagem em tubérculos, e para seu estudo da cinética de secagem da batata inglesa a $60^{\circ} \mathrm{C}$, os modelos de Page e de Handerson Pabis foram os que melhor se ajustaram.

\section{CONCLUSÃO}

Diante do exposto, pode-se concluir que no perfil cinético ocorreu uma redução do tempo com aumento da temperatura de secagem nas condições avaliadas, confirmando as leis que regem a transferência de calor e massa. Os resultados encontrados nas análises físico-químicas da fécula de batata-doce apresentaram padrões desejáveis de seus componentes avaliados. $\mathrm{O}$ teor de umidade, $\mathrm{pH}$, cinzas, fator ácido e acidez da fécula apresentaram valores conforme Resolução CNNPA no12 (ANVISA, 1978). Com relação a modelagem matemática, os modelos de Midilli e Kucuk, Page apresentaram os melhores ajustes aos dados experimentais, em relação aos três modelos em estudo.

\section{REFERÊNCIAS}

ALVES, J. A.; BOAS, E. V. B. V.; BOAS, B. M. V.; SOUZA, E. C.. Qualidade de produto minimamente processado à base de abóbora, cenoura, chuchu e mandioquinha-salsa. Ciência e Tecnologia de Alimentos, v.30, n.3, p.625-634, 2010.

ANVISA. Agência Nacional de Vigilância Sanitária. Resolução - CNNPA no 12, de 1978.

BORBA, A. M.; SARMENTO, S. B. S.; LEONEL, M.. Efeito dos parâmetros de extrusão sobre as propriedades funcionais de extrusados da farinha de batata-doce. Ciência e tecnologia de alimentos. v.25, n.4, Campinas, 2005

CANO-CHAUCA, M. RAMOS, A. M.; STRINGHETA, P. C.; MARQUES, J. A.; SILVA, P. I.. Curvas de secagem e avaliação da atividade de água da banana passa. Boletim do Centro de Pesquisa de Processamento de Alimentos, Curitiba, v.22, p.121-132, 2004

CARDOSO, A. D.; VIANA, A. E. S.; RAMOS, P. A. S.; MATSUMOTO, S. N.; AMARAL, C. L. F.; SEDIYAMA, T.; MORAIS, O. M.. Avaliação de Clones de Batata-doce em Vitória da Conquista. Horticultura Brasileira, v.23, n.4, p.911-914, 2005

GERALDI, C. A. Q.. Estudo da Secagem de Fécula de Mandioca em Secador do Tipo Pneumático: 'Flash Dryer' Dissertação (Mestrado em Engenharia Química) Universidade Estadual de Maringá, 2006. 
INTERNATIONAL STARCH INSTITUTE. Laboratory Methods Index, 1997.

SANTOS, J. C.; SOUZA, D. C. L.; SANTANA, M. M.; CASTRO, A. A.; SILVA, G. F.. Estudo da cinética de secagem da batatadoce. v.14, n.4, Campina Grande, 2012.
SILVA, R. G. V.. Caracterização físico-química de farinha de batata-doce para produtos de panificação. Dissertação

(Mestrado) - Universidade Estadual do Sudoeste da Bahia, Itapetinga, 2010.

SOUZA, A. K. R.. Elaboração e Avaliação do Purê de Batata Doce. Monografia (Bacharelado em Engenharia de Alimentos) - Universidade do Estado de Mato Grosso, 2016.

A CBPC - Companhia Brasileira de Produção Científica (CNPJ: 11.221.422/0001-03) detém os direitos materiais desta publicação. Os direitos referem-se à publicação do trabalho em qualquer parte do mundo, incluindo os direitos às renovações, expansões e disseminações da contribuição, bem como outros direitos subsidiários. Todos os trabalhos publicados eletronicamente poderão posteriormente ser publicados em coletâneas impressas sob coordenação da Sustenere Publishing, da Companhia Brasileira de Produção Científica e seus parceiros autorizados. Os (as) autores (as) preservam os direitos autorais, mas não têm permissão para a publicação da contribuição em outro meio, impresso ou digital, em português ou em tradução. 